\title{
Genetically engineered resistance for MMP collagenases promotes abdominal aortic aneurysm formation in mice infused with angiotensin II
}

\author{
Jun-o Deguchi ${ }^{1}$, Hayden Huang ${ }^{1}$, Peter Libby ${ }^{1}$, Elena Aikawa ${ }^{2}$, Peter Whittaker ${ }^{3}$, Jeremy Sylvan ${ }^{1}$, Richard T Lee \\ and Masanori Aikawa ${ }^{1}$
}

Clinical evidence links increased aortic collagen content and stiffness to abdominal aortic aneurysm (AAA) formation. However, the possibility that excess collagen contributes to AAA formation remains untested. We investigated the hypothesis that augmented collagen promotes AAA formation, and employed apoE-null mice expressing collagenaseresistant mutant collagen $\left(\mathrm{Col}^{\mathrm{R} / \mathrm{R}} / \mathrm{apoE}^{-/-}\right)$, heterozygote $\left(\mathrm{Col}^{\mathrm{R} /+} / \mathrm{apoE}^{-/-}\right)$, or wild-type collagen $\left(\mathrm{Col}^{+/+} / \mathrm{apoE}^{-/-}\right)$ infused with angiotensin II to induce AAA. As expected, the aortas of $\mathrm{Col}^{\mathrm{R} / \mathrm{R}} / \mathrm{apoE}^{-1-}$ mice contained more interstitial collagen than those from the other groups. Angiotensin II treatment elicited more AAA formation in $\mathrm{Col}^{\mathrm{R} / \mathrm{R}} / \mathrm{apoE}^{-1-} \mathrm{mice}^{-}$ than $\mathrm{Col}^{\mathrm{R} /+} / \mathrm{apoE}^{-/-}$or $\mathrm{Col}^{+/+} / \mathrm{apoE}^{-/-}$mice. Aortic circumferences correlated positively with collagen content, determined by picrosirius red and Masson trichrome staining. Mechanical testing of aortas of $\mathrm{Col}^{\mathrm{R} / \mathrm{R}} / \mathrm{apoE}^{-1-}$ mice showed increased stiffness and susceptibility to mechanical failure compared to those of $\mathrm{Col}^{+/+} / \mathrm{apoE}^{-/-}$mice. Optical analysis further indicated altered collagen fiber orientation in the adventitia of $\mathrm{Col}^{\mathrm{R} / \mathrm{R}} / \mathrm{apoE}^{-1-}$ mice. These results demonstrate that collagen content regulates aortic biomechanical properties and influences AAA formation.

Laboratory Investigation (2009) 89, 315-326; doi:10.1038/labinvest.2008.167; published online 19 January 2009

KEYWORDS: aneurysm; collagen; metalloproteinases; pathology; remodeling

The pathogenesis of abdominal aortic aneurysm (AAA) remains uncertain, and the lack of definitive insight suggests a complex, multifactorial process. ${ }^{1-4}$ AAA possesses major alterations in the content of extracellular matrix proteins: collagen and elastin. ${ }^{3,5-7}$ Interstitial collagen increases arterial stiffness, a property linked to AAA formation. ${ }^{8,9}$ Clinical evidence links increased arterial stiffness or collagen content to aortic aneurysms, whereas nonaneurysmal portions of aortas in AAA patients have showed increased collagen accumulation. ${ }^{10-20}$ However, whether collagen accumulation contributes causally to aneurysm formation or merely represents an epiphenomenon remains untested. To unravel the complex pathogenesis of AAA, we hypothesized that examination of both collagen content and its mechanical properties in mice with a genetic abnormality would provide novel insight.
To test directly in vivo whether aortic stiffness due to excess collagen accumulation promotes aneurysm formation, we used collagenase-resistant knock-in $\left(\mathrm{Col}^{\mathrm{R} / \mathrm{R}}\right)$ mice. ${ }^{21,22}$ This mouse strain bears a mutation in type I collagen, which comprises two-thirds of aortic collagen, at a cleavage site of the $\alpha 1$ (I) chain ( $\mathrm{Ile}^{776}$ to Pro $^{776}$ ) shared by collagenases of the matrix metalloproteinase (MMP) family (MMP-1/collagenase-1, MMP-8/collagenase-2 and MMP-13/collagenase-3). This mutation thus confers resistance to degradation, resulting in excess arterial collagen accumulation. ${ }^{22}$ Our study used angiotensin II (AngII) infusion to provoke AAA formation in apolipoprotein E-deficient $\left(\mathrm{apoE}^{-1-}\right)$ mice as established by Daugherty et al. ${ }^{23}$ AngII also stimulates collagen synthesis in vitro and induces collagen turnover and remodeling in the aortic wall of $\mathrm{apoE}^{-/-}$mice with features similar to human AAA. ${ }^{24-26}$

\footnotetext{
${ }^{1}$ Cardiovascular Division, Brigham and Women's Hospital, Harvard Medical School, Boston, MA, USA; ${ }^{2}$ Center for Molecular Imaging Research, Massachusetts General Hospital, Harvard Medical School, Charlestown, MA, USA and ${ }^{3}$ Cardiovascular Research Institute and Department of Emergency Medicine, Wayne State University School of Medicine, Detroit, MI, USA

Correspondence: Dr M Aikawa, MD, PhD, Center for Excellence in Vascular Biology, Brigham and Women's Hospital, Harvard Medical School, 77 Avenue Louis Pasteur, Boston, MA 02115, USA
}

E-mail: maikawa@rics.bwh.harvard.edu

Received 23 March 2008; revised 20 October 2008; accepted 29 October 2008 
Our results revealed that augmented collagen content induced by collagenase resistance modified the mechanical properties of the abdominal aortas of apoE $\mathrm{E}^{-1-}$ mice, and accelerated AAA formation. These data connect excess collagen accumulation and aortic stiffness to AAA formation, providing a novel potential mechanism for the pathogenesis of this complex disease process.

\section{MATERIALS AND METHODS}

\section{Animal Experiments and Tissue Preparation}

All mouse experiments conformed to protocols approved by the Standing Committee on Animals at Harvard Medical School. $\mathrm{Col}^{\mathrm{R} / \mathrm{R}}$ mice, backcrossed seven generations into C57BL/6, were crossed into apoE ${ }^{-1-}$ mice (C57BL/6), yielding littermates of $\mathrm{Col}^{\mathrm{R} / \mathrm{R}} / \mathrm{apoE}^{-/-}, \mathrm{Col}^{\mathrm{R} /+} / \mathrm{apoE}^{-/-}$, and $\mathrm{Col}^{+/+} / \mathrm{apoE}^{-1-}$ mice. ${ }^{22}$ Five-month-old male mice received AngII $\quad(1.44 \mathrm{mg} / \mathrm{kg} /$ day $)$ infusions for 4 weeks with subcutaneously implanted osmotic mini pumps (Alzet). Mice were anesthetized and perfused with $4 \%$ paraformaldehyde at a constant pressure of $100 \mathrm{~mm} \mathrm{Hg}$ through the heart. Aortas were dissected in the region of the superior mesenteric and right renal arteries and embedded with paraffin.

\section{Histological Analyses}

Sections (6- $\mu \mathrm{m}$ thick) were stained with Hematoxylin-Eosin, Masson trichrome, and picrosirius red. Aortic circumferences were measured on the histological sections by tracing the internal elastic lamina at the level of superior mesenteric artery in the aortas of AngII-infused $\mathrm{Col}^{+/+} / \mathrm{apoE}^{-1-}, \mathrm{Col}^{\mathrm{R} /+} /$ apoE ${ }^{-1-}$, and $\mathrm{Col}^{\mathrm{R} / \mathrm{R}} / \mathrm{apoE}^{-1-}$ mice $(n=8, n=6$, and $n=8$, respectively), using the NIH Image software (Research Services Branch, National Institute of Mental Health). Aortic diameter of each mouse was then obtained based on the circumference, which determined the incidence of AAA ( $>1.5$-fold greater than the aortas of mice untreated with AngII). Picrosirius red staining was viewed under polarized light to detect fibrillar collagen. ${ }^{22,27-29}$ Using picrosirius redor Masson-stained sections, adventitial collagen was measured in the tissue within $0.1 \mathrm{~mm}$ of the adventitial-medial border. Immunohistochemistry employed mouse monoclonal antibodies against human $\alpha$-smooth muscle actin (1A4; Dako) and human cathepsin S (Serotec) with a kit for immunohistochemistry using mouse primary antibodies on mouse tissues (Iso-IHC AEC kit; InnoGenex) and rat monoclonal antibody against mouse macrophages (Mac3; Pharmingen). Quantitative histological analysis on immunostaining and collagen staining used a digital imaging system (ImagePro Plus v5.1; Media Cybernetics). ${ }^{22,28}$

\section{RNA Extraction and Real-Time RT-PCR}

Total RNA extraction employed RNA-Bee (Tel-Test) and RNeasy (Qiagen) followed by reverse transcription using SuperScript II reverse transcriptase (Invitrogen). Real-time RT-PCR employed PRISM7900 with SYBR green Master
Mix (Applied Biosystems). Primer sequences are available on request.

\section{Mechanical Testing of Aortas}

To examine the effects of collagenase resistance on the mechanical properties of the aortas, strain experiments employed freshly isolated, unfixed preaneurysmal abdominal aortas of $\mathrm{Col}^{+/+} / \mathrm{apoE}^{-1-}(n=3)$ and $\mathrm{Col}^{\mathrm{R} / \mathrm{R}} / \mathrm{apoE}^{-1-}$ $(n=4)$ mice after AngII infusion (2 weeks). Parker MX80L electromechanical positioning system (Daedal Division) generated repetitive, controlled strains and ULC-1N load cell (Interface) recorded forces. Model SGA Strain Gauge Transducer Amplifier (Interface) passed through load cell signals. After determining a zero-point for each aorta, ie, when the aorta began to experience significant changes in restoring force, aorta length at zero-point was defined as the rest length. This measurement served to calculate subsequent strains for this aorta. The aorta was preconditioned with 300 cycles of $20 \%$ strain, then stressed for 10 cycles at $70 \%$ strain, both at $0.5 \mathrm{~Hz}$ frequency, and finally stretched to fracture (strain-to-break) by $5 \%$ strain increments up to $250 \%$ strain. The aorta's restoring forces were measured 20 times per cycle (10 times on extension and 10 times on relaxation), except for the strain-to-break experiment, which measured the forces at every $5 \%$ step. To determine the ultimate strength of the aortas, the strain-to-break experiment determined the stress and strain at the maximum force. The stresses, calculated by dividing the measured forces by the cross-sectional areas of the aorta, were reported as relative stresses to control stresses (which are normalized to 100\%) for each experiment. Stiffness was approximated linearly using the stress at $70 \%$ strain, normalized to the control conditions.

\section{Collagen Fiber Orientation}

To probe further the mechanisms that link increased aortic adventitial collagen content to mechanical failure in collagenase-resistant mice, we performed additional qualitative analysis of collagen organization in the nonaneurysm portions (in $\mathrm{Col}^{+/+} / \mathrm{apoE}^{-1-}$ and $\mathrm{Col}^{\mathrm{R} / \mathrm{R}} / \mathrm{apoE}^{-1-}$ mice after 2 weeks of AngII treatment) and aneurysm portions (in $\mathrm{Col}^{\mathrm{R} / \mathrm{R}} /$ $\mathrm{apoE}^{-1-}$ mice after 4 weeks of AngII) of the aortic tunica adventitia in a subset of animals ( $n=3$ for each group). Specifically, we examined and compared, using linearly polarized light and picrosirius red-stained sections, the collagen fiber extinction patterns seen in the three groups as the tissue sections were rotated on the microscope stage. When a fiber (or part of a fiber) is aligned parallel to the transmission axis of either of the microscope's two polarizing filters, it appears dark (said to be at extinction); at other orientations, the fiber appears bright. ${ }^{30}$ Thus, the extinction pattern provides information on collagen fiber organization.

\section{Statistics}

Differences between two groups and among three groups were determined using the unpaired Student's $t$-test and one- 
Table 1 Characteristics of mice

\begin{tabular}{|c|c|c|c|c|}
\hline & $\mathrm{Col}^{+/+} / \mathrm{apoE}^{-/-}(\mathrm{n}=8)$ & $\mathrm{Col}^{R /+} / \mathrm{apoE}^{-/-}(\mathrm{n}=6)$ & $\mathrm{Col}^{R / R} / \mathrm{apoE}^{-/-}(\mathrm{n}=8)$ & $P$ \\
\hline Body weight (g) & $31.6 \pm 0.6$ & $32.6 \pm 1.1$ & $30.9 \pm 0.9$ & NS \\
\hline Triglycerides (mg/100 ml) & $141.5 \pm 10.9$ & $118.0 \pm 25.2$ & $120.6 \pm 14.5$ & NS \\
\hline Systolic blood pressure ${ }^{\mathrm{a}}(\mathrm{mm} \mathrm{Hg})$ & $130.5 \pm 17.0$ & $134.6 \pm 23.8$ & $130.2 \pm 9.5$ & NS \\
\hline
\end{tabular}

Values are mean \pm s.e.m.

${ }^{\mathrm{a}}$ Measured in four animals of $\mathrm{Col}^{+/+} / \mathrm{apoE}^{-/-}$, four animals of $\mathrm{Col}^{\mathrm{R} / \mathrm{R}} / \mathrm{apoE}{ }^{-/-}$, and three animals of $\mathrm{Col}^{\mathrm{R} /+} / \mathrm{apoE}^{-/-}$.

way ANOVA followed by Tukey's test, respectively. Pearson's test examined the correlation between collagen content and aortic size. Statistical testing for stretching experiments was determined using the unpaired Student's $t$-test. To compare relative changes, we used a single-group comparison $t$-test to test the hypothesis that the mean relative change differs from zero.

\section{RESULTS}

Collagenase Resistance Accelerated AAA Formation in Angll-Treated apoE ${ }^{-1-}$ Mice

Body weight, plasma total cholesterol, and triglyceride levels in all three mouse strains treated with AngII did not differ significantly (Table 1). Elevated blood pressure may promote AAA formation. Among $\mathrm{Col}^{+/+} / \mathrm{apoE}^{-/-}, \mathrm{Col}^{\mathrm{R} /+} / \mathrm{apoE}^{-1-}$, and $\mathrm{Col}^{\mathrm{R} / \mathrm{R}} / \mathrm{apoE}^{-1-}$ strains, conscious blood pressure did not differ (Table 1). AngII increased the diameter of abdominal aortas at the level of the superior mesenteric artery in $\mathrm{Col}^{+/+} /$ apoE $^{-1-}$ mice (Figure 1a, left), as demonstrated by Daugherty et al..$^{23}$ However, $\mathrm{Col}^{\mathrm{R} / \mathrm{R}} / \mathrm{apoE}^{-1-}$ mice exhibited greater aneurysm formation than $\mathrm{did} \mathrm{Col}^{+/+} / \mathrm{apoE}^{-1-}$ mice (Figure 1a, right). Histological sections showed that $\mathrm{Col}^{\mathrm{R} / \mathrm{R}} /$ apoE ${ }^{-l-}$ aorta dilated more than those of similarly treated $\mathrm{Col}^{+/+} / \mathrm{apoE}^{-1-}$ mice (Figure 1b). Notably, the tunica intima rarely expanded in the abdominal aortas of these mice. We also observed no sign of rupture or thrombus formation in the aneurysmal aorta. Quantitative analysis demonstrated that the circumference of the aortas in $\mathrm{Col}^{\mathrm{R} / \mathrm{R}} /$ apoE $E^{-l-}$ mice exceeded that of $\mathrm{Col}^{\mathrm{R} /+} / \mathrm{apoE}^{-1-}$ or $\mathrm{Col}^{+/+} /$ $\mathrm{apoE}^{-/-}$mice (Figure 1c). AAA (>1.5-fold increases in diameter) developed in 50\% of AngII-infused $\mathrm{Col}^{+1+} /$ $\mathrm{apoE}^{-1-}$ mice (Figure 1d). The incidence was greater in $\mathrm{Col}^{\mathrm{R} /+} / \mathrm{apoE}^{-1-}(83 \%)$ and $\mathrm{Col}^{\mathrm{R} / \mathrm{R}} / \mathrm{apoE}^{-1-}$ mice $(100 \%)$. These results indicate that collagenase resistance accelerated AAA formation in a gene dosage-dependent manner.

\section{Collagenase Resistance Induced Excess Collagen Content in The Aortic Adventitia}

Defining whether collagenase resistance with AngII treatment promotes excess collagen accumulation entailed picrosirius red staining for quantification of the collagen content in the aortas. Quantification of picrosirius red staining viewed with polarization measures the content of fibrillar collagen, which comprises more than $90 \%$ of aortic collagen. ${ }^{5} \mathrm{Col}^{\mathrm{R} / \mathrm{R}} /$ $\mathrm{apoE}^{-1-}$ mice had more fibrillar collagen in aortas localized in the adventitia than $\mathrm{Col}^{+/+} / \mathrm{apoE}^{-/-}$mice (Figure 2a). Masson trichrome staining, another histological assay for collagen, also demonstrated more prominent collagen accumulation in the adventitia of $\mathrm{Col}^{\mathrm{R} / \mathrm{R}} / \mathrm{apoE}^{-/-}$mice (Figure 2b). Further, quantitative analysis of collagen content determined by picrosirius red and Masson trichrome staining demonstrated more abundant adventitial collagen in the aortas of $\mathrm{Col}^{\mathrm{R} / \mathrm{R}} / \mathrm{apoE}^{-1-}$ mice vs $\mathrm{Col}^{\mathrm{R} /+} / \mathrm{apoE}^{-1-}$ and $\mathrm{Col}^{+/+} / \mathrm{apoE}^{-1-}$ mice (Figure 2c). Real-time RT-PCR showed slightly decreased levels of type I procollagen $\alpha 1$ mRNA in the aortas of $\mathrm{Col}^{\mathrm{R} / \mathrm{R}} / \mathrm{apoE}^{-/-}$mice compared to those of $\mathrm{Col}^{+/+} / \mathrm{apoE}^{-1-}$ mice (Figure $2 \mathrm{~d}$ ). These results suggest that impaired collagen degradation by collagenases of the MMP family, but not increased synthesis, accounts for the greater collagen accumulation in the aortic adventitia of $\mathrm{Col}^{\mathrm{R} / \mathrm{R}} / \mathrm{apoE}^{-1-}$ mice.

\section{Collagen Content in the Adventitia Correlated with Size of the Aorta}

As $\mathrm{Col}^{\mathrm{R} / \mathrm{R}} / \mathrm{apoE}^{-1-}$ mice had both increased collagen accumulation and accelerated formation of AAA, we tested the hypothesis that aortic collagen content correlates with abdominal aortic dimension. Regression analysis demonstrated that adventitial collagen content correlated positively with aorta circumferences in AngII-treated apoE ${ }^{-/-}$mice, as determined by both picrosirius red and Masson trichrome staining (Figure 3 ).

\section{Collagenase Resistance Promoted Disruption of Medial Elastic Laminae, but did not Induce Expression of Elastases or Collagenases}

Aneurysms characteristically have disrupted medial elastic laminae. In this study, the aortas of $\mathrm{Col}^{\mathrm{R} / \mathrm{R}} / \mathrm{apoE}^{-1-}$ mice exhibited more prominent, but focal, medial disruption compared to the aortas of $\mathrm{Col}^{-1-} / \mathrm{apoE}^{-1-}$ mice (Figure 4a). However, medial disruption of $\mathrm{Col}^{\mathrm{R} / \mathrm{R}} / \mathrm{apoE}^{-/-}$mice aortas did not colocalize with either macrophage accumulation, a major source of various elastolytic enzymes, or immunoreactive cathepsin S, a key elastase in vascular remodeling (Figure $4 \mathrm{~b}$ ). 
a

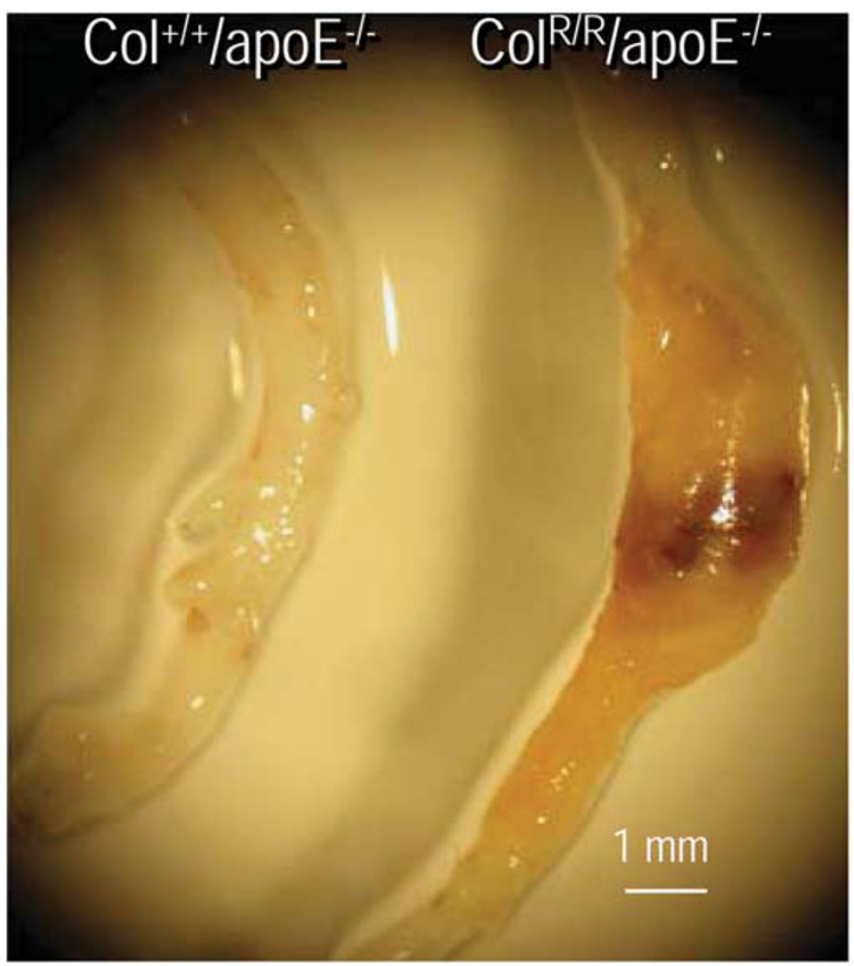

C $(\mathrm{mm})$

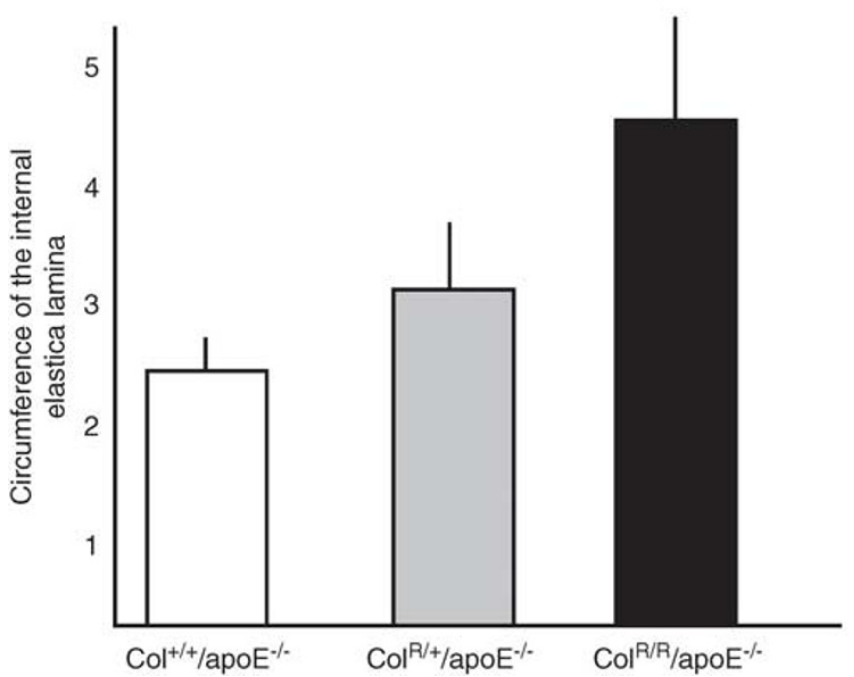

b
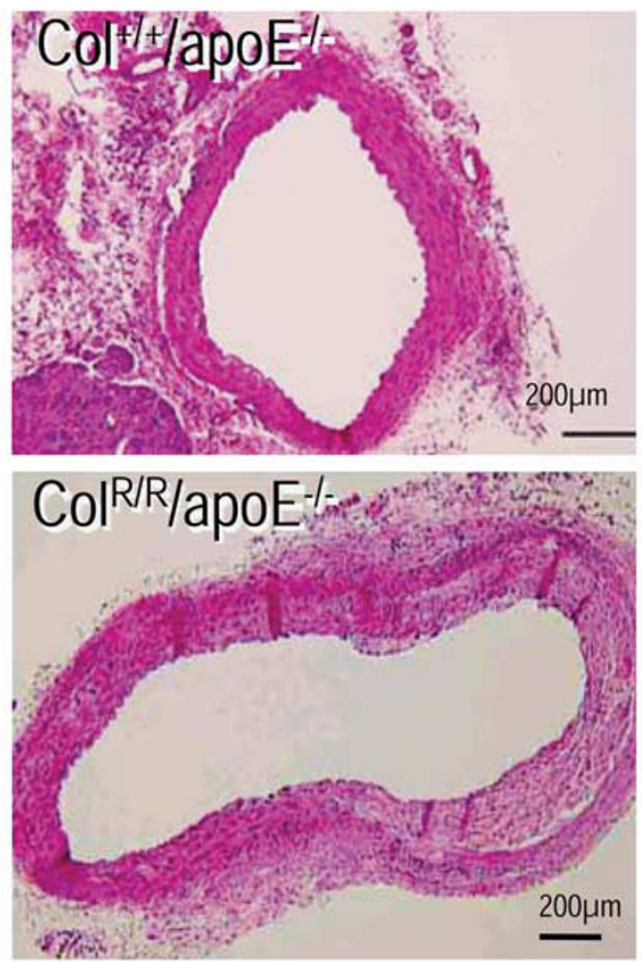

d

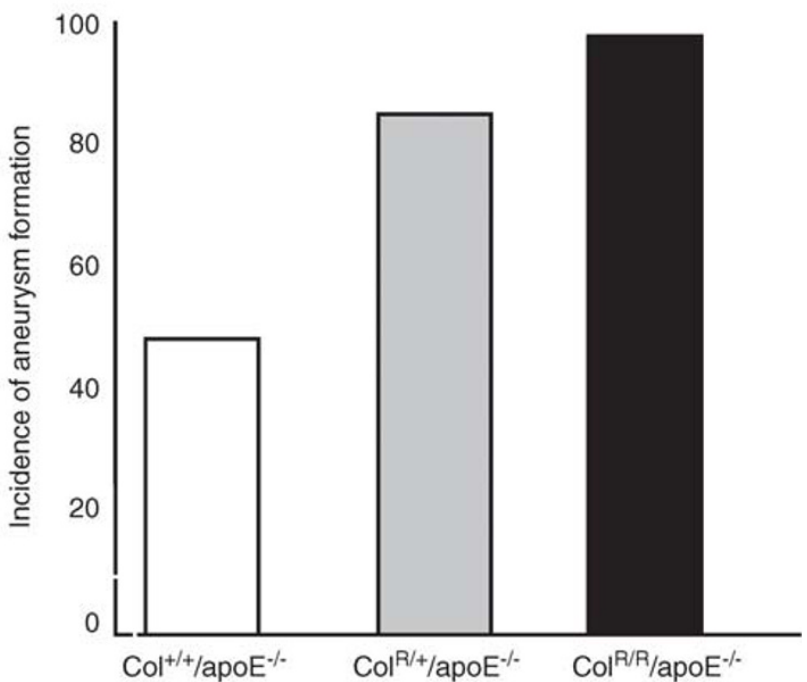

Figure 1 Collagenase resistance accelerated AAA formation. (a) Representative gross appearance of abdominal aortas of Angll-treated $\mathrm{Col}^{+/+} / \mathrm{apoE}^{-/-}$ (left) or $\mathrm{Col}^{\mathrm{R} / \mathrm{R}} / \mathrm{apoE}{ }^{-/-}$(right) mice. (b) Representative Hematoxylin-Eosin staining of the abdominal aortas from $\mathrm{Col}^{+/+} / \mathrm{apoE}^{-/-}$(top) and $\mathrm{Col}^{\mathrm{R} / \mathrm{R}} / \mathrm{apoE}{ }^{-/-}$ (bottom) mice. The aortic wall protrudes and extends to the right in the $\mathrm{Col}^{\mathrm{R} / \mathrm{R}} / \mathrm{apoE}^{-1-}$ mouse. (c) Quantitative analysis of circumference of the internal lamina. $\mathrm{Col}^{\mathrm{R} / \mathrm{R}} / \mathrm{apoE}{ }^{-/-}$mice $(n=8)$ had greater abdominal aortas compared with $\mathrm{Col}^{+/+} / \mathrm{apoE}^{-1-}(n=6)$ or $\mathrm{Col}^{+/+} / \mathrm{apoE}^{-1-} \mathrm{mice}^{(n=8)}$. Bars and error bars represent mean and s.e.m, respectively. (d) Collagenase resistance also increased the incidence of AAA formation ( $>1.5$-fold increase in diameter).

To address the potential role of the changes in smooth muscle cells, we performed immunohistochemistry for smooth muscle $\alpha$-actin in the aortas of mice treated with AngII. In all nonaneurysmal regions, the majority of medial smooth muscle cells stained positively for $\alpha$-actin in both groups (Figure 4c). In contrast, in aneurysmal segments of $\mathrm{Col}^{+/+}$and $\mathrm{Col}^{\mathrm{R} / \mathrm{R}}$ mice, the disrupted medial smooth muscle cell layer did not contain detectable levels of $\alpha$-actin. These results were reproducible in all animals with no substantial differences between wild-type and collagenaseresistant mutant mice.

Germline manipulation of a gene in mice could cause 'compensatory' changes in other genes that share similar functions with the targeted gene. Such responses could 
a

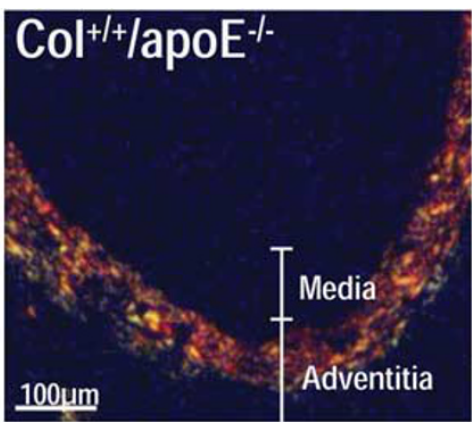

b

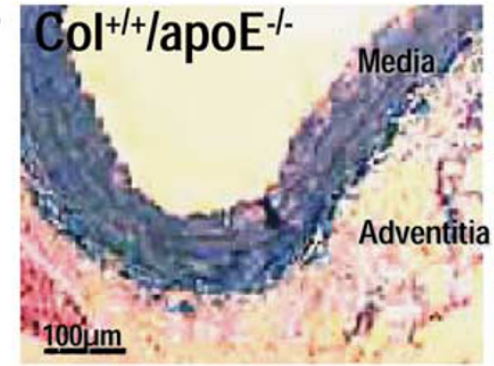

c

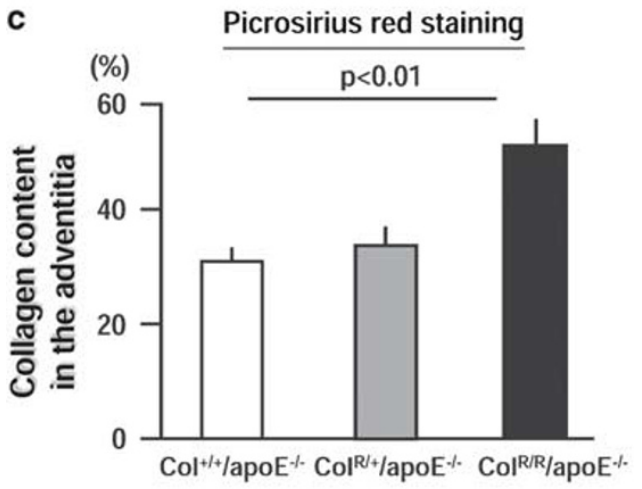

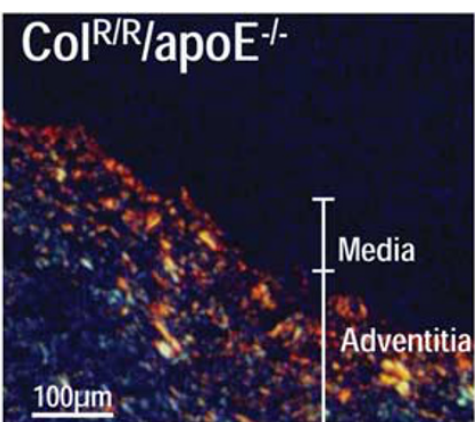
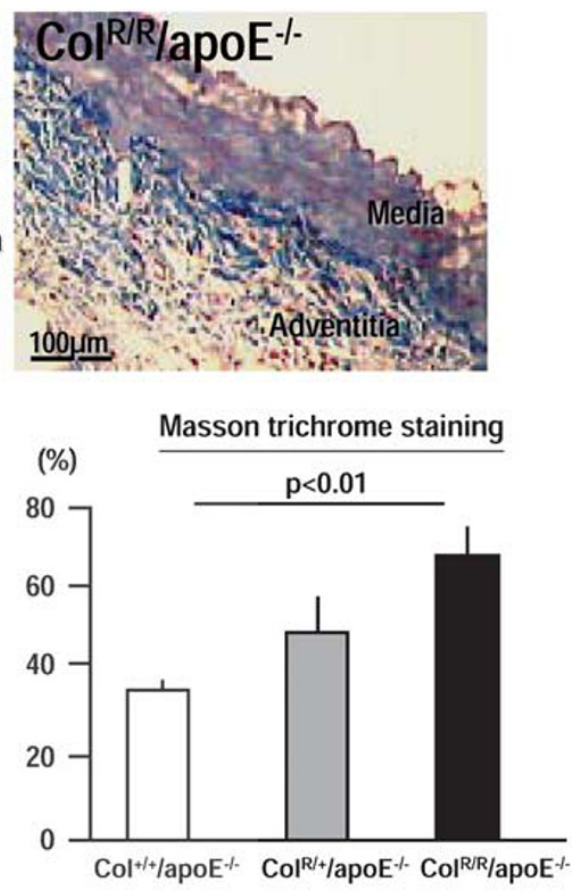

d $\alpha-1$ pro-collagen mRNA

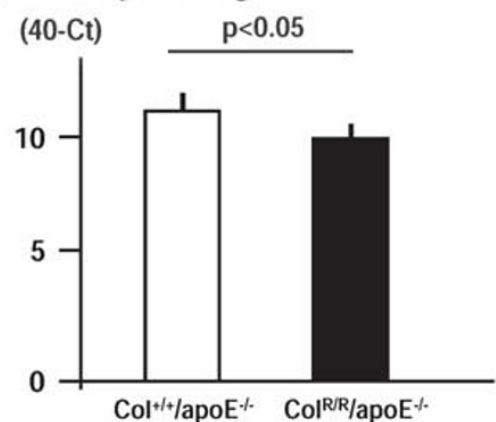

Figure 2 Collagen accumulates in the adventitia. (a) Representative cross sections stained with picrosirius red viewed under polarization. (b) Masson trichrome staining on cross sections adjacent to those shown in (a). (c) Quantitative analysis of collagen content in the adventitia, determined by picrosirius

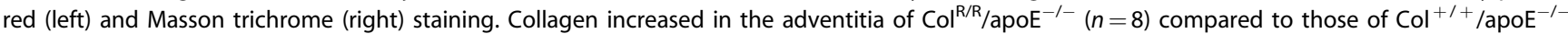

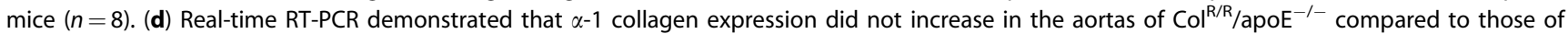

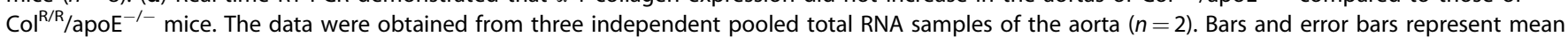
and s.e.m, respectively.

hinder data interpretation and require careful consideration. Indeed, our previous study of acute myocardial infarction in MMP-9-deficient mice yielded unexpected results likely due to increases in other MMPs. ${ }^{31}$ Therefore, this study examined expression of several elastases including MMP-9, MMP-12 (MMP family elastases), and cathepsin S (a major non-MMP 
elastase) to evaluate whether compensatory increases could contribute to elastolysis. Quantitative real-time RT-PCR demonstrated that GAPDH-adjusted levels of mRNAs encoding MMP-9, MMP-12, and cathepsin S in the AngIItreated aortas did not differ between $\mathrm{Col}^{\mathrm{R} / \mathrm{R}} / \mathrm{apoE}^{-1-}$ and $\mathrm{Col}^{+/+} / \mathrm{apoE}^{-1-}$ mice (Figure 5a). Additionally, we evaluated the expression of these elastases in macrophages, the major source of matrix-degrading proteinases in aortas. Collagenase resistance did not affect elastase gene expression in peritoneal macrophages from $\mathrm{Col}^{\mathrm{R} / \mathrm{R}} / \mathrm{apoE}^{-1-}$ mice compared to those from $\mathrm{Col}^{+/+} / \mathrm{apoE}^{-1-}$ mice (Figure $5 \mathrm{~b}$ ). We further evaluated expression of interstitial collagenases (MMP-8 and MMP-13). In particular, MMP-13, the major interstitial collagenase in mice (a species that lacks MMP-1), has elastase activity ${ }^{32}$ and converts pro-MMP-9 into its active form. ${ }^{33}$ AngII-treated aortas and peritoneal macrophages of $\mathrm{Col}^{\mathrm{R} / \mathrm{R}} / \mathrm{apoE}^{-1-}$ and $\mathrm{Col}^{+/+} / \mathrm{apoE}^{-1-}$ mice expressed similar levels of MMP-8 and MMP-13 mRNAs (Figure 5a and b).

\section{Collagenase Resistance Increased Aortic Stiffness and Promoted Susceptibility to Mechanical Failure}

To test further the hypothesis that aortic stiffness due to excess collagen accumulation impairs resistance of the aorta to mechanical stresses, we examined the biomechanical properties of preaneurysmal aortas obtained from $\mathrm{Col}^{+/+}$/

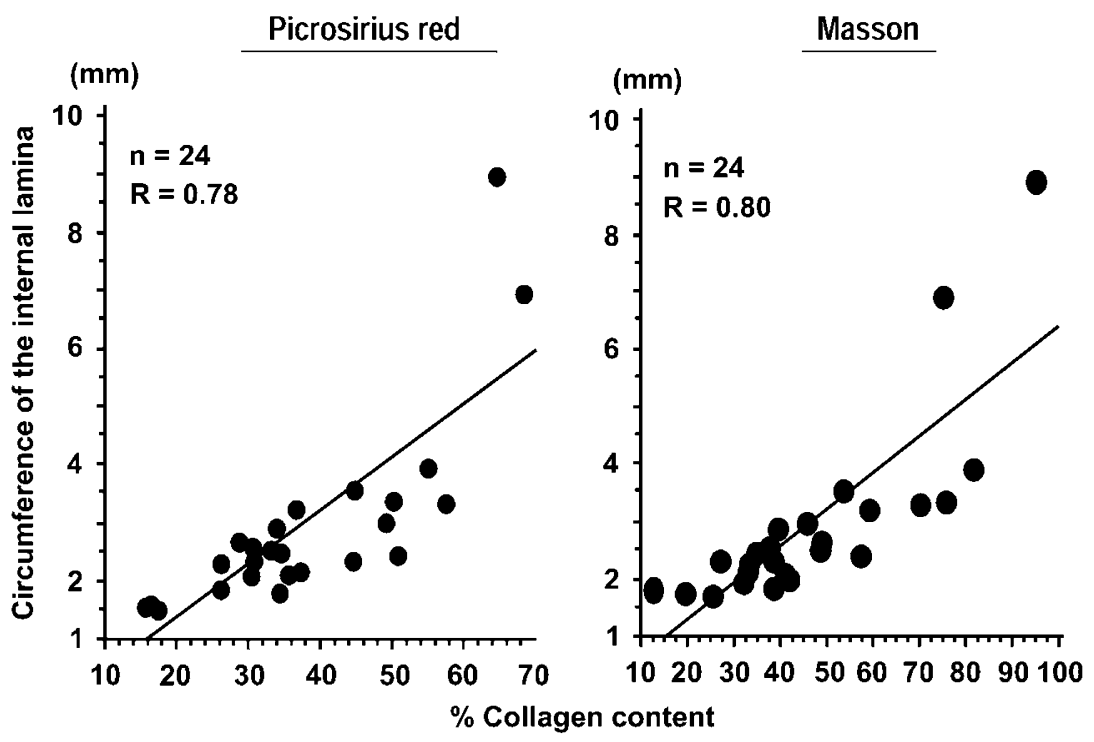

Figure 3 Collagen content in the adventitia correlates with the size of aortas. Left, correlation between circumference of the internal lamina and percentage of picrosirius-red positive areas in the adventitia. Right, correlation between circumference of the internal lamina and the percentage of Masson trichromepositive areas in the adventitia. The data were obtained from all apo: ${ }^{-1-}$ mice studied $(n=24)$.

Figure 4 Elastin disruption in aortas of $\mathrm{Col}^{\mathrm{R} / \mathrm{R}} / \mathrm{apoE}^{-/-}$mice following Angll infusion. (a) Elastica von Gieson staining demonstrates disrupted medial elastin in aortas of $\mathrm{Col}^{+/+} / \mathrm{apoE}^{-/-}$and $\mathrm{Col}^{\mathrm{R} / \mathrm{R}} / \mathrm{apoE}^{-/-}$mice. Note that $\mathrm{Col}^{\mathrm{R} / \mathrm{R}} / \mathrm{apoE}{ }^{-1-}$ showed marked loss of medial elastin (right side). (b) Immunohistochemistry for macrophages (Mac-3), smooth muscle cells ( $\alpha$-actin), and cathepsin $S$ in aortic wall of $\mathrm{Col}^{\mathrm{R} / \mathrm{R}} / \mathrm{ApoE}^{-1-}$ mouse. The same section was stained with Elastica von Gieson. Disrupted medial elastin (arrow) did not colocalize with macrophages or immunoreactive cathepsin S. (c) In nonaneurysmal regions, the majority of medial smooth muscle cells stained positively for $\alpha$-actin in both $\mathrm{Col}^{+/+}$and $\mathrm{Col}^{\mathrm{R} / \mathrm{R}}$ mice. In contrast, in aneurysmal segments of both groups, the disrupted medial smooth muscle cell layer did not contain detectable levels of $\alpha$-actin. These results were reproducible in all animals with no substantial differences between $\mathrm{Col}^{+/+}$and $\mathrm{Col}^{\mathrm{R} / \mathrm{R}}$ mice $(n=8$ each).
$\mathrm{apoE}^{-/-}$and $\mathrm{Col}^{\mathrm{R} / \mathrm{R}} / \mathrm{apoE}^{-/-}$mice after 2 weeks of AngII infusion. The $70 \%$-strain cycles assessed durability, whereas the strain-to-break experiments aimed to gauge the ultimate strength of the aortas (Figure 6a). As expected, the aortas of $\mathrm{Col}^{\mathrm{R} / \mathrm{R}} / \mathrm{apoE}^{-1-}$ mice exhibited increased initial stiffness at the first $70 \%$ strain (after preconditioning) compared to those of $\mathrm{Col}^{+/+} / \mathrm{apoE}^{-/-}$mice (Figure $6 \mathrm{~b}$ ). However, stiffness decreased more rapidly in the aortas of $\mathrm{Col}^{\mathrm{R} / \mathrm{R}} / \mathrm{apoE}^{-1-}$ mice after 10 cycles of the $70 \%$ strain than those of $\mathrm{Col}^{+/+} /$ $\mathrm{apoE}^{-1-}$ mice, suggesting higher susceptibility to fatiguetype failure in collagenase-resistant aortas (Figure 6c).

Examining whether the aortas of $\mathrm{Col}^{\mathrm{R} / \mathrm{R}} / \mathrm{apoE}^{-1-}$ mice have impaired resistance to stretch required the strain-tobreak test. Based on the stresses at failure, we found significantly lower ultimate stresses on the aortas of $\mathrm{Col}^{\mathrm{R} / \mathrm{R}}$ / $\mathrm{apoE}^{-1-}$ mice $v s \mathrm{Col}^{+/+} / \mathrm{apoE}^{-/-}$mice (Figure 6d). Thus, the collagen-enriched aortas of the collagenase-resistant animals are more fragile and more easily broken by deformation

\section{Collagenase Resistance Altered Collagen Orientation in the Aortic Adventitia}

address the potential mechanism for the paradoxical as sociation of increased collagen accumulation in the aortas of $\mathrm{Col}^{\mathrm{R} / \mathrm{R}}$ mice and susceptibility to rapid fatigue and ultimate 
a

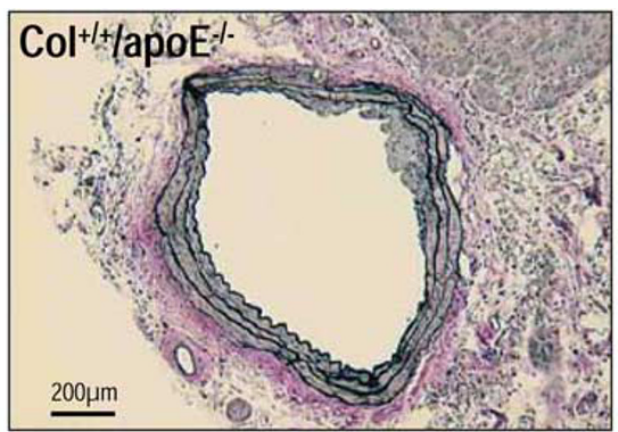

b
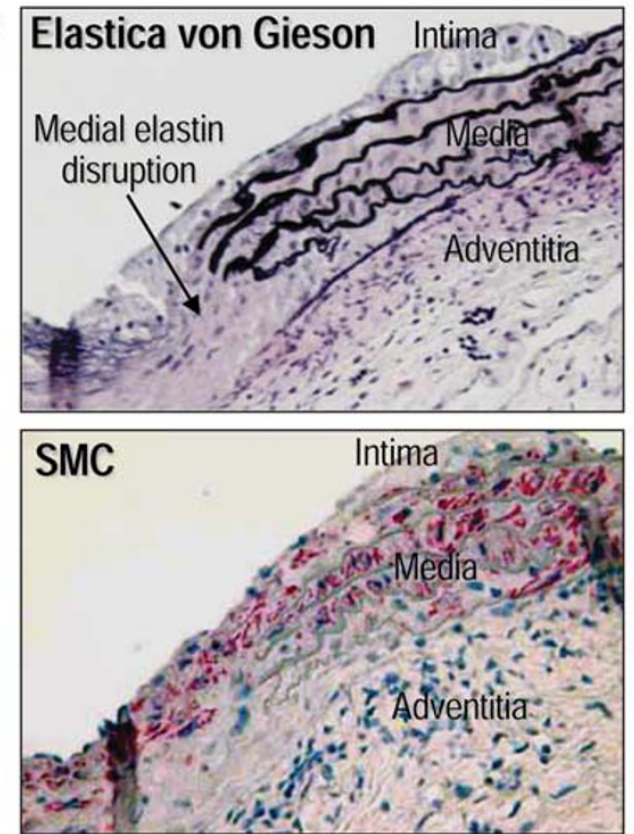

c

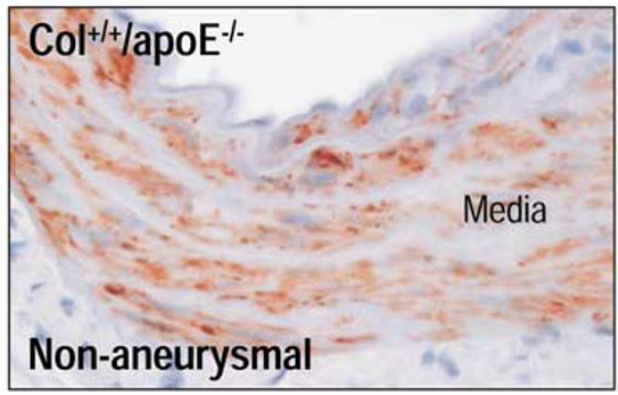

\section{$\mathrm{Col}^{+/+} / \mathrm{apoE}-1-$}

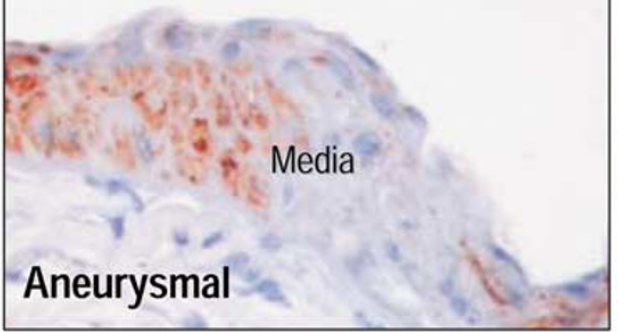

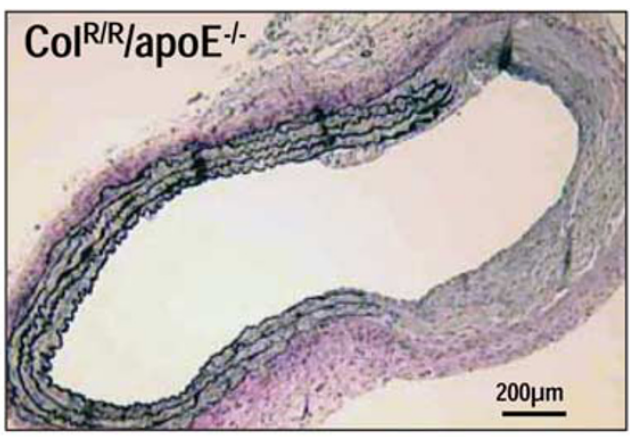
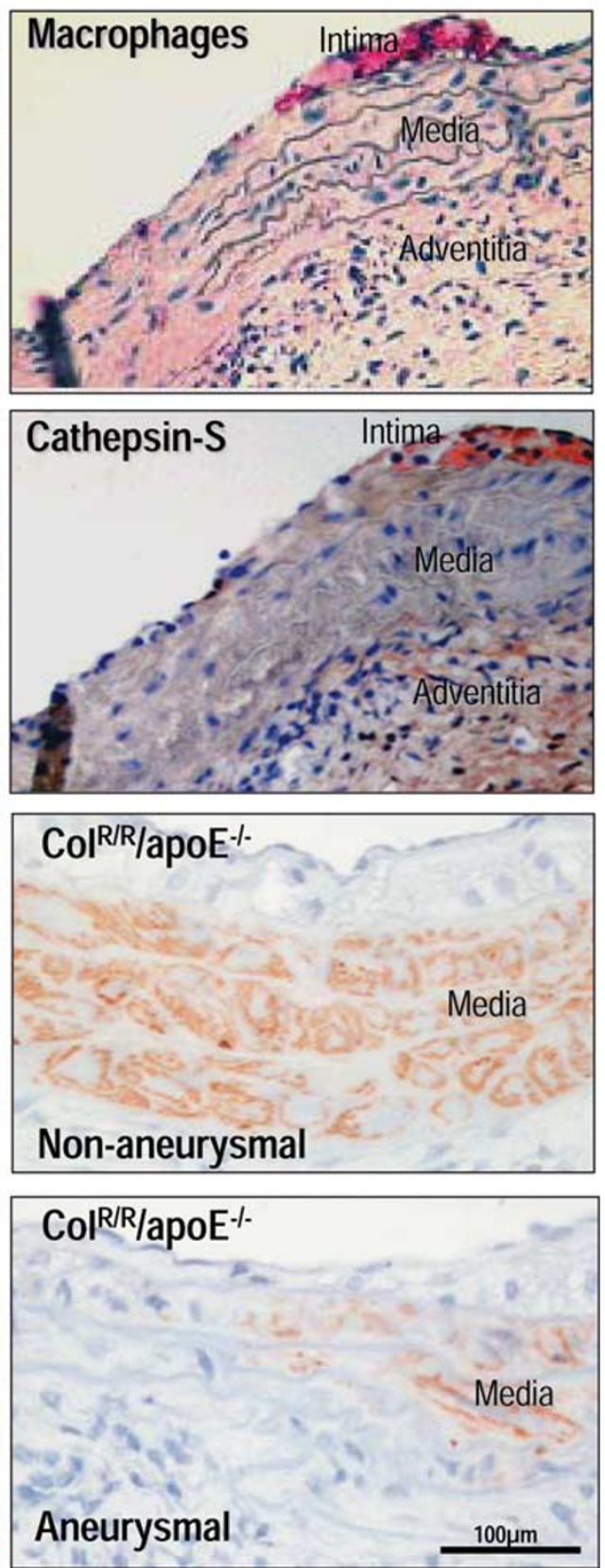

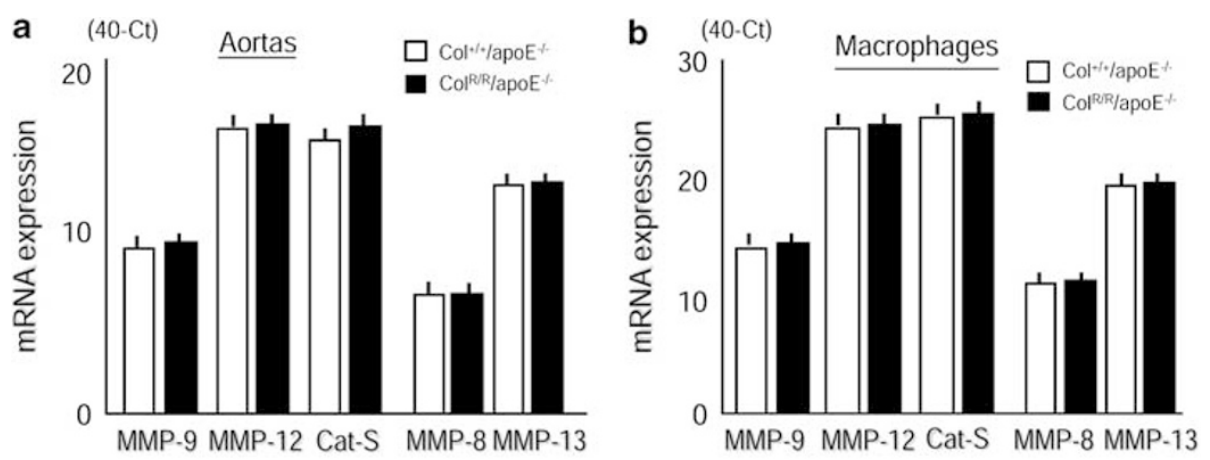

Figure 5 Collagenase resistance did not cause compensatory changes in elastolytic and collagenolytic enzymes. Real-time PCR demonstrated similar mRNA levels of MMP elastases (MMP-9 and MMP-12), MMP collagenase (MMP-8 and MMP-13), and cathepsin S (Cat-S) in aortas treated with Angll for 2 weeks from $\mathrm{Col}^{+/+} / \mathrm{ApoE}^{-1-}$ or $\mathrm{Col}^{\mathrm{R} / \mathrm{R}} / \mathrm{apoE}^{-/-}$mice (a) and in thioglycollate-treated peritoneal macrophages (b) from Col ${ }^{+/+} / \mathrm{apoE}^{-1-}$ or $\mathrm{Col}^{\mathrm{R} / \mathrm{R}} / \mathrm{apoE}^{-/-} \mathrm{mice}^{-}$The data were obtained from three independent pooled total RNA samples of the aorta $(n=2)$ or three different preparations of peritoneal macrophages. Bars and error bars represent mean cycle numbers $(\Delta C T$ : 40 - threshold cycle numbers) and s.e.m.

disruption, we subsequently examined whether collagen orientation changed in collagenase-resistant mice. Figure 7 illustrates both schematic and actual representative extinction patterns seen with different collagen fiber architecture. The extinction pattern observed in the aneurysm wall corresponded to that expected for straight fibers (Figure $7 \mathrm{a}$ and b, top panels), whereas the banded extinction pattern frequently observed in the adventitia of $\mathrm{Col}^{\mathrm{R} / \mathrm{R}}$ aortas indicated two-dimensional fiber waviness (Figure $7 \mathrm{a}$ and $\mathrm{b}$, middle panels). In contrast, the narrow band of extinction frequently observed to sweep across fibers in the adventitia of the wildtype samples echoed fibers whose waviness possesses a threedimensional helical component (Figure $7 \mathrm{a}$ and $\mathrm{b}$, bottom panels). These results reveal major differences in collagen fiber architecture in the adventitia. In contrast, we observed no structural changes or differences between wild-type and collagenase-resistant mutant mice in the medial collagen fibers of the nonaneurysmal segments of the aorta (data not shown).

\section{DISCUSSION}

Multiple biomechanical and biological factors, including smoking, hypertension, shear or circumferential stress, aging, and atherosclerosis, may contribute to the development of AAA. ${ }^{5,6,19}$ Such risk factors can influence the metabolism of the aortic extracellular matrix and promote ongoing structural matrix remodeling, a characteristic of AAA. Collagen and elastin comprise the two major extracellular matrix constituents of the aorta. Regulation of both elastin and collagen content in the abdominal aorta appears dynamic. ${ }^{5,6,19}$ Clinical evidence indicates an important role for aortic stiffness and/or excess collagen in aneurysm formation. ${ }^{10-16}$ Therefore, this study tested the hypothesis that excess collagen accumulation due to impaired collagen catabolism during aortic remodeling promotes AAA formation.
Daugherty et $a l^{23}$ found that AngII treatment in apoE $\mathrm{E}^{-/-}$ mice produces AAA. AngII also increases arterial collagen turnover: production and degradation. ${ }^{24-26}$ Our study used AngII-treated apoE ${ }^{-1-}$ mice bearing a mutation that renders collagen type I collagenase-resistant to induce greater aortic collagen accumulation than those expressing wild-type collagen and to test whether excess collagen accelerates AAA formation. Interstitial collagens, especially type I collagen, consist of a triple helix of polypeptide chains that resist degradation by most proteases except the interstitial collagenases. ${ }^{21,34}$ Unperturbed collagenase-resistant mice show no overt vascular phenotype. ${ }^{21}$ Indeed, without AngII treatment, $\mathrm{Col}^{\mathrm{R} / \mathrm{R}} / \mathrm{apoE}^{-/-}$mice do not develop aneurysm (data not shown). We found more prominent AAA formation and collagen accumulation in AngII-treated $\mathrm{Col}^{\mathrm{R} / \mathrm{R}} /$ $\mathrm{apoE}^{-1-}$ mice.

Collagen provides mechanical integrity to the arterial wall and regulates various biological functions of vascular cells. ${ }^{8,35}$ Adventitial fibrillar collagen generally confers tensile mechanical strength on the aorta. ${ }^{5}$ Collagen also contributes to aortic stiffness. ${ }^{8}$ Compared to the aortas of $\mathrm{Col}^{+/+} / \mathrm{apoE}^{-1-}$ mice, increased collagen in the aortas of $\mathrm{Col}^{\mathrm{R} / \mathrm{R}} / \mathrm{apoE}^{-l-}$ mice led to increased stiffness, as demonstrated by our mechanical testing (Figure 6b). However, this increased stiffness did not provide durability to the aorta (Figure $6 \mathrm{c}$ and $\mathrm{d}$ ). Rather, compared to $\mathrm{Col}^{+/+} / \mathrm{apoE}^{-1-}$ mice, the aortas of $\mathrm{Col}^{\mathrm{R} / \mathrm{R} /}$ $\mathrm{apoE}^{-l-}$ mice experienced more rapid loss of stiffness as well as mechanical failure at lower stresses, indicating that excess collagen accumulation promoted susceptibility to mechanical failure.

The apparent paradoxical association of increased aortic collagen accumulation in $\mathrm{Col}^{\mathrm{R} / \mathrm{R}}$ mice and susceptibility to rapid mechanical fatigue and eventual tissue disruption requires further consideration, even though our findings concur with clinical evidence linking aortic stiffness and increased collagen with aneurysm formation. ${ }^{10-15}$ Collagen's 

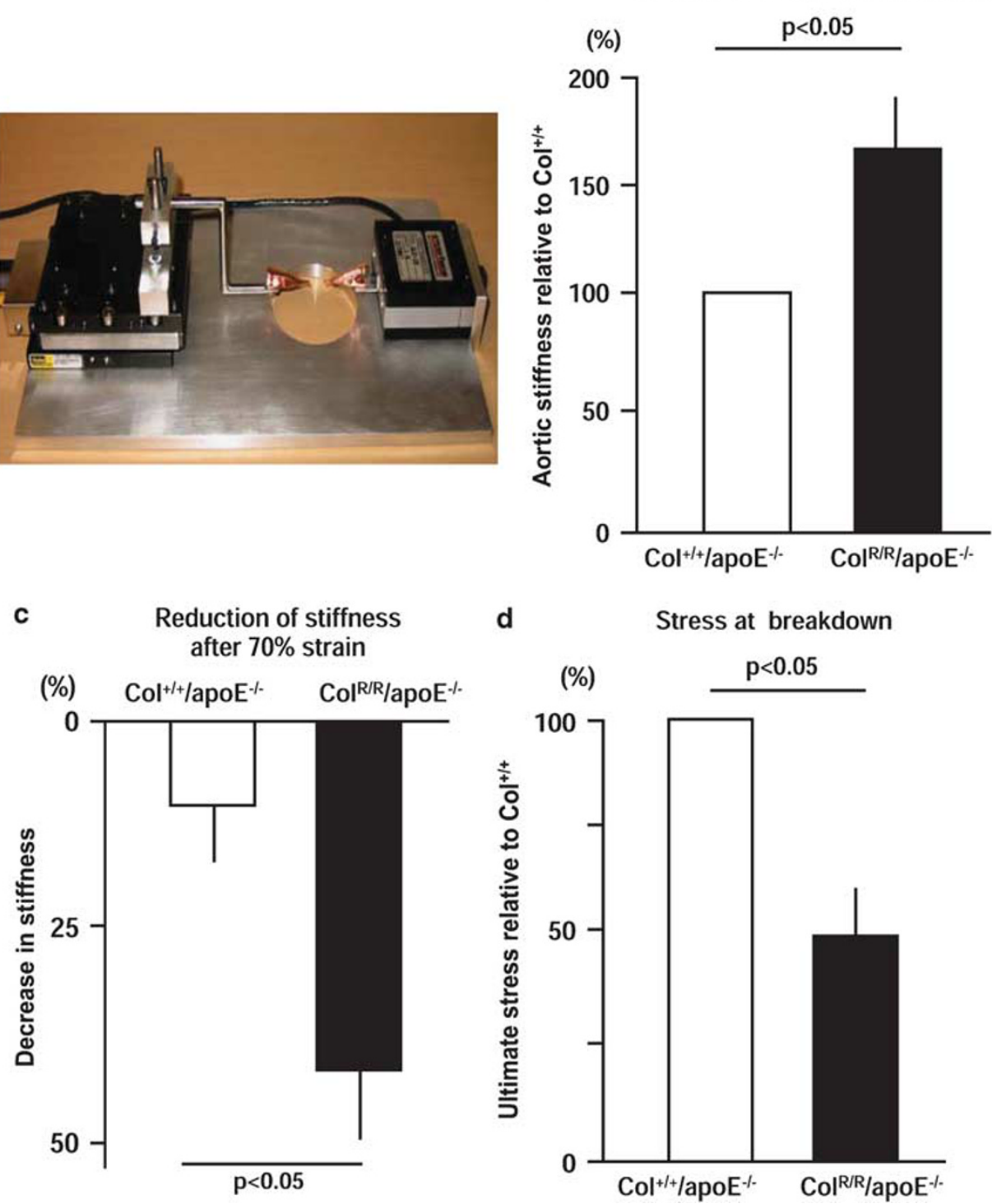

Figure 6 Mechanical testing of the aorta. (a) The strain-device used to measure the mechanical response of aortas to cyclic strain and strain failure. The load cell is on the right and the electromechanical positioning system is on the left. The aorta is clamped in the center above the hole. (b) Aortic stiffness of $\mathrm{Col}^{\mathrm{R} / \mathrm{R}} / \mathrm{apoE}{ }^{-1-}$ mice is $65 \%$ higher, on average, compared to $\mathrm{Col}^{+/+} / \mathrm{apoE}^{-1-}$ mice. (c) After 10 cycles of $70 \% \mathrm{strain}^{\mathrm{C} \mathrm{Col}^{\mathrm{R} / \mathrm{R}} / \mathrm{apoE}}{ }^{-1-}$ aortas showed a significant reduction in stiffness compared to $\mathrm{Col}^{+/+} / \mathrm{apoE}^{-/-}$aortas $\left(\mathrm{Col}^{\mathrm{R} / \mathrm{R}} / \mathrm{apoE}^{-1-}: 32 \%\right.$ decrease, $\mathrm{Col}^{\mathrm{R} / \mathrm{R}} / \mathrm{apoE}{ }^{-/-}: 8 \%$ decrease in stiffness before $70 \%$ strain test). (d) Aortas of $\mathrm{Col}^{\mathrm{R} / \mathrm{R}} / \mathrm{apoE}^{-/-}$mice failed under stresses at $48 \%$ of the failure, compared to $\mathrm{Col}^{+/+} / \mathrm{apoE}^{-1-}$ aortas. These assays employed a subset of $\mathrm{Col}^{+/+} / \mathrm{apoE}^{-1-}(n=3)$ and $\mathrm{Col}^{\mathrm{R} / \mathrm{R}} / \mathrm{apoE}^{-1-}$ mice $(n=4)$.

mechanical properties depend not only on its quantity and biochemical properties, but also on the fiber architecture. We indeed found substantial architectural differences between groups in the subset of mice studied in this regard. Normal arterial adventitial collagen organization displays a three-dimensional helical waviness; ${ }^{36}$ the extinction patterns observed in our wild-type samples reflect such an organization (Figure 7). In our study, aortic adventitial collagen assumed a more two-dimensional, but still wavy, structure in $\mathrm{Col}^{\mathrm{R} / \mathrm{R}}$ mice (probably to accommodate the collagen increase). Additional remodeling resulted in fiber straigh- tening in the aneurysm wall. Assuming the absence of concurrent biochemical changes, such structural alterations would associate with increased tissue stiffness. In tissues subject to pulsatile or multiaxial deformation, the compliance provided by three-dimensional fiber waviness probably provides mechanical advantage. For example, skin possesses a three-dimensional structure and exhibits extinction patterns ${ }^{37}$ similar to those of the $\mathrm{Col}^{+/+}$ adventitia. In contrast, collagen fibers in tendons, prone to rupture due to mechanical stresses, have a predominantly two-dimensional structure and extinction patterns ${ }^{30}$ similar 
a
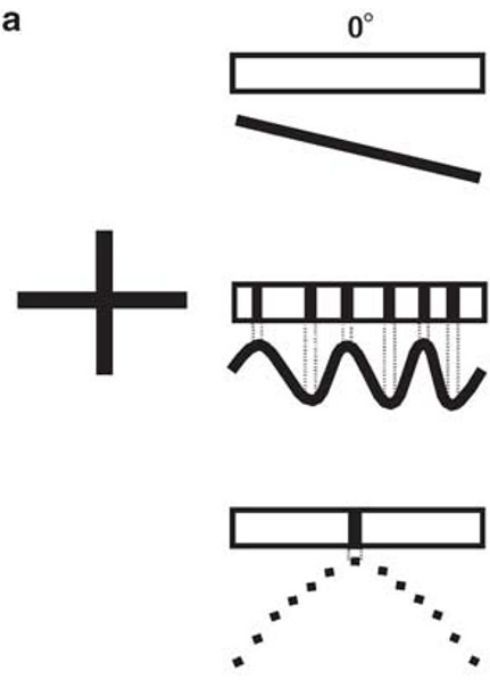

b
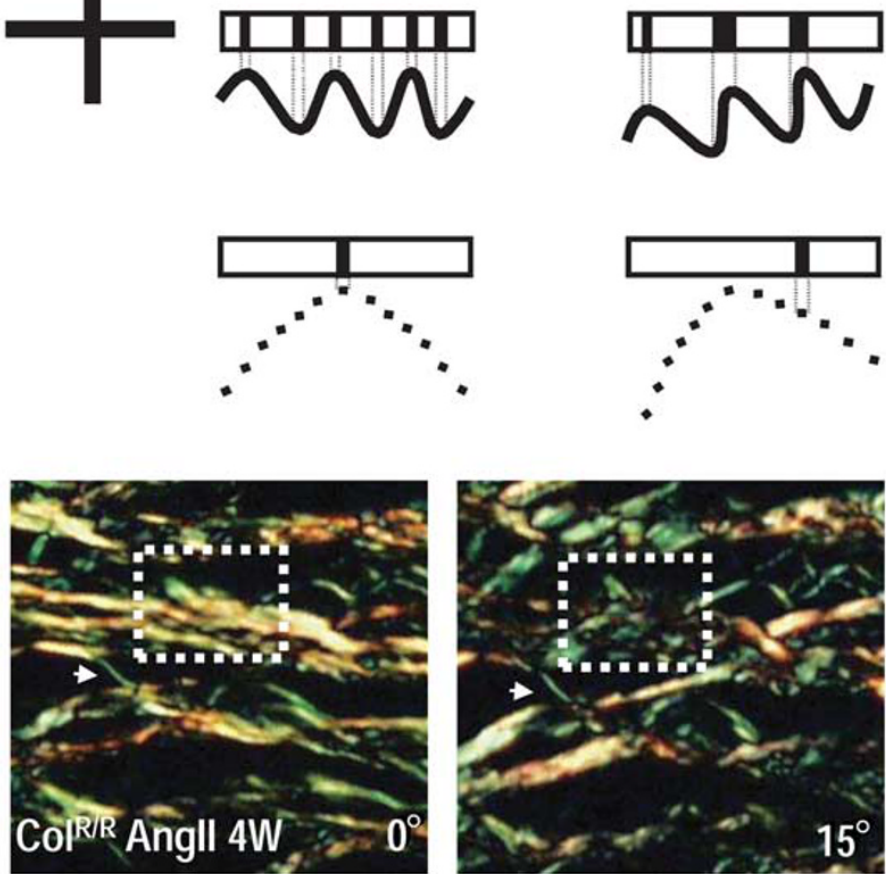

$15^{\circ}$
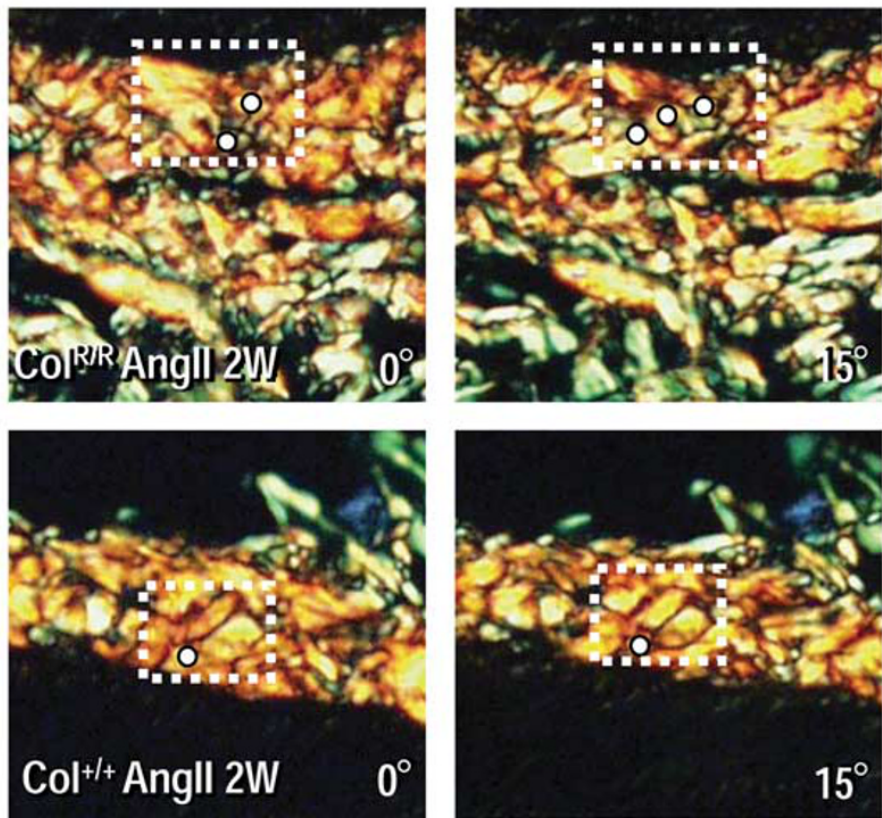

$30^{\circ}$
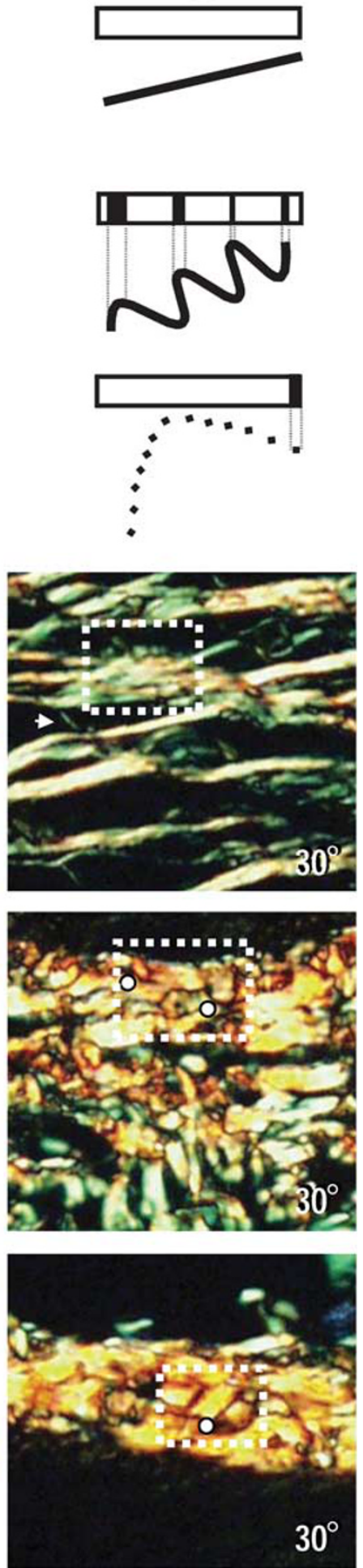

to those seen in the adventitia and aneurysm of $\mathrm{Col}^{\mathrm{R} / \mathrm{R}}$ tissue. We propose that these architectural changes in the adventitia agree with our mechanical data and explain why collagen accumulation induced by collagenase resistance paradoxically increases susceptibility to mechanical failure. We observed no structural differences between groups in the collagen fibers or smooth muscle cells in the media of the nonaneurysmal aortic segments. Nonetheless, these observations were not 
Figure 7 Collagen extinction patterns viewed with linearly polarized light provide an indication of fiber organization. (a) Schematic extinction patterns for three fiber configurations at three orientations (the cross indicates the alignment of the polarizers' transmission axes). When collagen is aligned parallel to either transmission axis, it appears dark. At all other orientations, it appears bright. The upper row of each schematic shows the extinction pattern that reflects fiber orientation illustrated in the lower row (dotted line connects fiber segments aligned parallel to a transmission axis to corresponding extinction pattern). Top: No portion of the straight fiber in the first column $\left(0^{\circ}\right)$ is parallel to a transmission axis and so appears bright. When rotated by $15^{\circ}$ (second column), the entire fiber is parallel to the horizontal transmission axis and appears dark. When rotated an additional $15^{\circ}$ (third column), the fiber again appears bright. Middle: Portions of the wavy fiber are parallel to a transmission axis, and hence a banded extinction pattern results. A $15^{\circ}$ rotation brings different portions parallel to the transmission axes, producing a different banded pattern. Additional rotation changes the pattern again. Bottom: A fiber with three-dimensional waviness, ie, a helical structure (dashed line). In the first column, only a small portion of this fiber is aligned parallel to a transmission axis and a single narrow extinction band results; the rest of the fiber appears bright. Additional $15^{\circ}$ rotations bring different regions to extinction-a narrow extinction band sweeps across the fiber. (b) Actual aortic tissue extinction patterns. Top: Aneurysm collagen from a collagenase-resistant mouse (4-week Angll). An arrow marks the fiber of interest and an arrowhead a fiber that appears bright in each panel. The entire marked fiber appears dark in the middle panel, but bright in the others-consistent with a straight fiber. Middle: Preaneurysmal Col ${ }^{R / R}$ tissue (2-week Angll). Different fiber portions appear dark at each orientation (white dots placed immediately below the dark area)-consistent with two-dimensional waviness. Bottom: Wild-type (2-week Angll). With rotation, a narrow extinction band sweeps across the marked fiber-consistent with three-dimensional waviness. The white dot lies approximately at the end of the band of extinction in each panel. These data represent three different mice per group that produced similar results.

made in regions directly involved in aneurysm formation and therefore whether medial changes occur during the initial development of the aneurysm remains to be determined.

Accumulating evidence suggests that MMPs participate in various aspects of cardiovascular remodeling including aneurysm formation. ${ }^{2,3,22,27-29,38-44}$ Previous studies including our own showed that MMP elastases and collagenases increase in the wall of human AAA.,38-40 Degradation of the extracellular matrix in the aortic wall may cause aneurysmal changes, and animal studies suggest that MMPs participate in aneurysm formation. ${ }^{2,3,38-44}$ Understanding further mechanisms of aneurysm formation involving MMPs should provide important insights into therapeutic strategies for this disease. This study did not attempt to determine the role of MMPs in the pathogenesis of aneurysms, but tested the specific hypothesis that excess collagen accelerates AAA formation, using mice that resist cleavage by MMP family collagenases. We were also aware that if MMP collagenases play a role in AAA formation, introducing a loss-of-function phenotype due to collagenase resistance could decrease the incidence of AAA, contrary to our originally anticipated results. The data showed that collagenase resistance yielded foci of substantial aortic dilatation in AngII-treated apoE ${ }^{-/-}$ mice, supported further by mechanical testing data. In addition, collagenase resistance did not cause compensatory increases of mRNA that encode major elastases. Collectively, these results suggest that augmented formation of AAA in this particular study depends primarily on accumulation of uncleavable fibrillar collagen, but not directly on changes in matrix-degrading enzymes.

Our study demonstrates that collagenase resistance promotes excessive collagen accumulation in aortic adventitia and modifies aortic mechanical properties, in turn accelerating aneurysm formation. These results in genetically altered mice provide mechanistic insights into the pathogenesis of AAA formation, specifically linking collagen content and organization to the aorta's mechanical properties. Furthermore, these associations implied by our results combined with the novel finding of altered collagen architecture provide a basis for future investigation of the structural and mechanical aspects of AAA formation.

\section{ACKNOWLEDGEMENTS}

This work was in part supported by grants from the NHLBI (HL-56985 to Dr Libby and Dr Aikawa, HL-66086 to Dr Aikawa, HL-80472 to Dr Libby, HL-67249 to Dr Sukhova), and the Donald W Reynolds Foundation (Dr Libby). Dr Deguchi received a fellowship from the Reynolds Foundation. We acknowledge Dr Stephen M Krane for creating $\mathrm{Col}^{R / R}$ mice and helpful suggestions, Mr Francisco U Cruz for his assistance with stretching experiments, and Ms Joan Perry for her editorial expertise.

1. Ernst CB. Abdominal aortic aneurysm. N Engl J Med 1993;328: 1167-1172.

2. Thompson RW. Aneurysm treatments expand. Nat Med 2005;11: 1279-1281.

3. Allaire $\mathrm{E}$, Forough $\mathrm{R}$, Clowes $\mathrm{M}$, et al. Local overexpression of TIMP-1 prevents aortic aneurysm degeneration and rupture in a rat model. J Clin Invest 1998;102:1413-1420.

4. Touat Z, Ollivier V, Dai J, et al. Renewal of mural thrombus releases plasma markers and is involved in aortic abdominal aneurysm evolution. Am J Pathol 2006;168:1022-1030.

5. Tilson MD, Gregory AK, Hingorani AP. Aneurysmal Disease of the Abdominal Aorta. Futura Publishing Company: New York, 1997.

6. Thompson RW, Geraghty PJ, Lee JK. Abdominal aortic aneurysms: basic mechanisms and clinical implications. Curr Probl Surg 2002;39:110-230.

7. Shimizu K, Libby $P$, Mitchell RN. Local cytokine environments drive aneurysm formation in allografted aortas. Trends Cardiovasc Med 2005;15:142-148.

8. Lee RT, Kamm RD. Vascular mechanics for the cardiologist. J Am Coll Cardiol 1994;23:1289-1295.

9. Sumner DS. Essential Hemodynamic Principles. In: Rutherford RB (ed). Vascular Surgery, 5th edn. W.B. Saunders Company: Philadelphia, 2000, pp 73-120.

10. Baxter BT, Davis VA, Minion DJ, et al. Abdominal aortic aneurysms are associated with altered matrix proteins of the nonaneurysmal aortic segments. J Vasc Surg 1994;19:797-802; discussion 803.

11. Sonesson B, Hansen F, Lanne T. Abdominal aortic aneurysm: a general defect in the vasculature with focal manifestations in the abdominal aorta? J Vasc Surg 1997;26:247-254.

12. Simons $P C$, Algra A, Bots $M L$, et al. Common carotid intima-media thickness in patients with peripheral arterial disease or abdominal aortic aneurysm: the SMART study. Second Manifestations of ARTerial disease. Atherosclerosis 1999;146:243-248.

13. Dijk JM, van der Graaf $Y$, Grobbee $D E$, et al. Increased arterial stiffness is independently related to cerebrovascular disease and aneurysms of the abdominal aorta: the Second Manifestations of Arterial Disease (SMART) Study. Stroke 2004;35:1642-1646. 
14. Cheng KS, Tiwari A, Morris R, et al. The influence of peripheral vascular disease on the carotid and femoral wall mechanics in subjects with abdominal aortic aneurysm. J Vasc Surg 2003;37:403-409.

15. Loeys BL, Chen J, Neptune ER, et al. A syndrome of altered cardiovascular, craniofacial, neurocognitive and skeletal development caused by mutations in TGFBR1 or TGFBR2. Nat Genet 2005;37:275-281.

16. He CM, Roach MR. The composition and mechanical properties of abdominal aortic aneurysms. J Vasc Surg 1994;20:6-13.

17. Menashi S, Campa JS, Greenhalgh RM, et al. Collagen in abdominal aortic aneurysm: typing, content, and degradation. J Vasc Surg 1987;6:578-582.

18. Minion DJ, Davis VA, Nejezchleb PA, et al. Elastin is increased in abdominal aortic aneurysms. J Surg Res 1994;57:443-446.

19. Glickman BS, Rehm JP, Baxter BT. Arterial Aneurysm: Etiologic Consideration. In: Rutherford RB (ed). Vascular Surgery, 5th edn. W. B. Sanders Company: Philadelphia, 2000; 373-386.

20. Rizzo RJ, McCarthy WJ, Dixit SN, et al. Collagen types and matrix protein content in human abdominal aortic aneurysms. J Vasc Surg 1989;10:365-373.

21. Liu $X$, Wu $H$, Byrne $M$, et al. A targeted mutation at the known collagenase cleavage site in mouse type I collagen impairs tissue remodeling. J Cell Biol 1995;130:227-237.

22. Fukumoto $Y$, Deguchi J, Libby $P$, et al. Genetically determined resistance to collagenase action augments interstitial collagen accumulation in atherosclerotic plaques. Circulation 2004;110: 1953-1959.

23. Daugherty A, Cassis LA. Mouse models of abdominal aortic aneurysms Arterioscler Thromb Vasc Biol 2004;24:429-434.

24. Ford CM, Li S, Pickering JG. Angiotensin II stimulates collagen synthesis in human vascular smooth muscle cells. Involvement of the AT(1) receptor, transforming growth factor-beta, and tyrosine phosphorylation. Arterioscler Thromb Vasc Biol 1999;19:18431851.

25. Tham DM, Martin-McNulty B, Wang YX, et al. Angiotensin II injures the arterial wall causing increased aortic stiffening in apolipoprotein E-deficient mice. Am J Physiol Regul Integr Comp Physiol 2002;283:R1442-R1449.

26. Satta J, Juvonen T, Haukipuro K, et al. Increased turnover of collagen in abdominal aortic aneurysms, demonstrated by measuring the concentration of the aminoterminal propeptide of type III procollagen in peripheral and aortal blood samples. J Vasc Surg 1995;22: 155-160.

27. Deguchi J, Aikawa E, Libby P, et al. Matrix metalloproteinase-13/ collagenase-3 deletion promotes collagen accumulation and organization in mouse atherosclerotic plaques. Circulation 2005;112:2708-2715.

28. Aikawa M, Rabkin E, Okada $\mathrm{Y}$, et al. Lipid lowering by diet reduces matrix metalloproteinase activity and increases collagen content of rabbit atheroma: a potential mechanism of lesion stabilization. Circulation 1998;97:2433-2444.
29. Aikawa $E$, Whittaker $P$, Farber $M$, et al. Human semilunar cardiac valve remodeling by activated cells from fetus to adult: implications for postnatal adaptation, pathology, and tissue engineering. Circulation 2006;113:1344-1352.

30. Whittaker P, Canham PB. Demonstration of quantitative fabric analysis of tendon collagen using two-dimensional polarized light microscopy. Matrix 1991;11:56-62.

31. Ducharme A, Frantz S, Aikawa $M$, et al. Targeted deletion of matrix metalloproteinase- 9 attenuates left ventricular enlargement and collagen accumulation after experimental myocardial infarction. J Clin Invest 2000;106:55-62.

32. Knauper V, Lopez-Otin C, Smith B, et al. Biochemical characterization of human collagenase-3. J Biol Chem 1996;271:1544-1550.

33. Knauper V, Smith B, Lopez-Otin C, et al. Activation of progelatinase B (proMMP-9) by active collagenase-3 (MMP-13). Eur J Biochem 1997;248:369-373.

34. Brinckerhoff CE, Matrisian LM. Matrix metalloproteinases: a tail of a frog that became a prince. Nat Rev Mol Cell Biol 2002;3: 207-214.

35. Pickering JG. Regulation of vascular cell behavior by collagen: form is function. Circ Res 2001;88:458-459.

36. Finlay HM, Whittaker P, Canham PB. Collagen organization in the branching region of human brain arteries. Stroke 1998;29: 1595-1601.

37. Beck LS, DeGuzman L, Lee WP, et al. One systemic administration of transforming growth factor-beta 1 reverses age- or glucocorticoidimpaired wound healing. J Clin Invest 1993;92:2841-2849.

38. Thompson RW, Holmes DR, Mertens RA, et al. Production and localization of 92-kilodalton gelatinase in abdominal aortic aneurysms. An elastolytic metalloproteinase expressed by aneurysm-infiltrating macrophages. J Clin Invest 1995;96:318-326.

39. Curci JA, Liao S, Huffman MD, et al. Expression and localization of macrophage elastase (matrix metalloproteinase-12) in abdominal aortic aneurysms. J Clin Invest 1998;102:1900-1910.

40. Knox JB, Sukhova GK, Whittemore AD, et al. Evidence for altered balance between matrix metalloproteinases and their inhibitors in human aortic diseases. Circulation 1997;95:205-212.

41. Allaire $E$, Hasenstab D, Kenagy RD, et al. Prevention of aneurysm development and rupture by local overexpression of plasminogen activator inhibitor-1. Circulation 1998;98:249-255.

42. Lemaitre V, Soloway PD, D'Armiento J. Increased medial degradation with pseudo-aneurysm formation in apolipoprotein E-knockout mice deficient in tissue inhibitor of metalloproteinases-1. Circulation 2003;107:333-338.

43. Longo GM, Xiong W, Greiner TC, et al. Matrix metalloproteinases 2 and 9 work in concert to produce aortic aneurysms. J Clin Invest 2002;110:625-632

44. Pyo R, Lee JK, Shipley JM, et al. Targeted gene disruption of matrix metalloproteinase-9 (gelatinase B) suppresses development of experimental abdominal aortic aneurysms. J Clin Invest 2000;105:1641-1649. 